Debangshu Ghosh, MS'

Dilip Kumar Baruah, MS (ENT)

Subodh Chandra Goswami, MS (ENT) ${ }^{3}$

Sumit Kumar Basu, MS (ENT)'

'Department of ENT

R.G.Kar Medical College and Hospital,

Kolkata,West Bengal, India

2 Private Practitioner

Guwahati, Assam, India

${ }^{3}$ Department of ENT

Guwahati Medical College

Guwahati, Assam, India
Correspondence: Dr. Debangshu Ghosh

Kalyan Nagar (Near K.G. School)

P.O.-Kalyan Nagar, Via-Panshila, Dist.-24

Parganas (North), Kolkata- 700112 West Bengal

India

Phone: +9133 9038336301/ +913325680293

E-mail: ghoshdr.d777@ymail.com

Reprints will not be available from the author.

The authors declared that this represents original material that is not being considered for publication or has not been published or accepted for publication elsewhere in full or in part, in print or electronic media; that the manuscript has been read and approved by all the authors, that the requirements for authorship have been met by each authors, and that each authorbelieves that the manuscript represents honest work. Disclosures: The authors signed disclosures that there are no financial or other (including personal) relationships, intellectual passion, political or religious beliefs, and institutional affiliations that might lead to a conflict of interest.

\section{Lateral Rhinotomy for a Large, Infected Haller Cell Causing Proptosis}

\begin{abstract}
Objective: To report a case of a large sinus Haller cell that presented with chronic rhinosinusitis and proptosis and its surgical management.

\section{Methods:}

Design: Case Report

Setting: Tertiary Government Hospital

Patient: One

Results: A 34-year-old lady with proptosis and secondary sinusitis due to a giant infected Haller cell was successfully treated by lateral rhinotomy approach and clearance of all diseased mucosa therein into the nasal cavity.
\end{abstract}

Conclusion: Approach to diseased sinonasal structures via lateral rhinotomy is an alternative to endoscopic sinus surgery in the presence of an unusually large Haller cell.

Keywords: Haller cell, proptosis, maxillary sinusitis, lateral rhinotomy

'Haller cells' - named after Swedish anatomist Albrecht von Haller are abnormally migrated anterior or posterior ethmoid air cells that may pneumatize the roof of the maxillary sinus. With an incidence reported to vary from $2-45 \%,{ }^{1}$ Haller cells are usually seen in the inferomedial wall or floor of the orbit (i.e. roof of the maxillary sinus) at the level between medial and inferior rectus, adjacent to and above the natural ostium of maxillary sinus. Although a Haller cell is considered a normal anatomical variant, when enlarged it can significantly constrict the posterior aspect of the ethmoidal infundibulum and maxillary ostium from above. If such a cell becomes diseased, the natural ostium of the maxillary sinus may rapidly become obstructed and secondary maxillary sinusitis may develop. A statistically significant increase in maxillary sinus mucosal disease was associated with medium to large Haller cells $(45.8 \%)$ compared with small cells $(28.9 \%, p<0.05){ }^{2}$ An unusually large Haller cell also hinders the approach to other sinonasal diseasesed structures during endoscopic sinus surgery. The prevalence of Haller cells on panoramic radiographs is $38.2 \%$ but the incidence with which they are seen in a normal population may be less frequent than in individuals with chronic rhinosinusitis. ${ }^{3}$ Diagnosis of Haller cells is typically made by CT scans as they cannot be identified by diagnostic nasal endoscopy because of their typical location lateral to the infundibulum. Sinoscopic examination of the maxillary antrum can also identify an enlarged or diseased Haller cell. Only diseased Haller cells or large cells blocking the ethmoidal infundibulum need to be addressed surgically and endoscopic resection of such cells remains the 


\section{CASE REPORTS}

treatment of choice. Surgical intervention is also indicated when a Haller cell contributes to ostiomeatal complex obstruction and inflammation of the sinuses. We report the case of a large infected Haller cell causing proptosis and maxillary sinusitis that achieved complete remission after the cell was excised through a lateral rhinotomy approach instead of endoscopically.

\section{CASE REPORT}

A 34-year-old woman presented in the Department of ENT of Gauhati Medical College \& Hospital with progressive frontal headache and nasal congestion for one year, right-sided nasal obstruction with on-and-off foul, purulent nasal discharge and outward protrusion of the right eyeball for six months, and a painful, red swelling below the right medial canthus for 10 days with intermittent fever. She was initially diagnosed with preseptal orbital cellulitis resulting from acute on chronic maxillary sinusitis and was started on broad-spectrum systemic antibiotics, topical and systemic nasal decongestants. The headache started insidiously and initially localized to the right side only before it became generalized. There were no changes in vision, nasal bleeding, weight loss or swelling in the neck or anywhere else in the body. Unrelieved after consulting several ophthalmologists, she attended the ENT department and was admitted. The patient was normotensive, non-diabetic, on average diet and an occasional betel-nut chewer. She was not immunocompromised and there was no significant past or family history.

On general survey, she was afebrile with pulse rate of $70 / \mathrm{min}$ and BP-110/70 mmHg. There was a tense, mildly tender fluctuant swelling situated just below the right inner canthus with reddening of superficial skin. The right eye was superolaterally displaced but visual acuity and intraocular pressure were normal. (Figure 1) On anterior rhinoscopy there was a well-circumscribed fleshy mass arising from the right lateral nasal wall that did not bleed on probing. On nasal endoscopy with a $0^{\circ} 4 \mathrm{~mm}$ telescope, the swelling was seen to arise from the lateral nasal wall in the region of the middle turbinate axilla beyond which the endoscope could not be passed and the exact origin of the mass could not be determined. Initially, occipitomental radiographs did not reveal any abnormality except right-sided maxillary sinusitis. Paranasal and orbit CT scans revealed a large, well-defined, fairly hypodense lesion along the roof of the right maxillary sinus showing fairly formed bony walls. It showed severe mass effect compressing the maxillary sinus and nasal cavity and distorting the ostiomeatal unit, middle turbinate, frontal recess and ethmoid sinus without sclerosis or erosion of surrounding bones. The mass encroached into the orbit causing displacement of the medial rectus and inferior rectus muscle and intraconal fat and causing proptosis of the globe. (Figure 2) The overall impression was of a large Haller nasi cell with mass effect on right sinonasal structures. Punch biopsy revealed congested and inflamed tissue lined by epithelium.

Broad-spectrum parenteral antibiotics were started according to our hospital protocol, consisting of Cefotaxime-Sulbactum and Tinidazole along with an analgesic and oral decongestant. Owing to the palpable swelling in the medial canthus of the right eye, we opted for a lateral rhinotomy (Moore) incision for easy access and wide exposure. Immediately beneath the subcutaneous tissue in the superomedial portion of the maxillary sinus roof, a $1.5 \mathrm{~cm}$ diameter mass lined by a thin bony capsule was punctured yielding frank pus. The sac was freely communicating with the ipsilateral nasal cavity. Proptosis decreased immediately and the inferomedial orbital wall was intact. (Figure 3) The wound was closed in layers and an antibiotic-impregnated anterior nasal pack was inserted. Postoperative antibiotics were given for 7 days and the nasal pack and stitches were removed after 48 hours and 7 days, respectively.

The patient was regularly followed up and was doing well at 2 weeks, 1 month and 6 months with no recurrence of symptoms. (Figure 4)

\section{DISCUSSION}

Since the development of endoscopic sinus surgery techniques, pneumatization of anatomic structures of the nose and paranasal sinuses has become a topic of increasing importance to rhinologists. Anatomic variations in the nose and sinuses do not necessarily indicate a pathologic state but can predispose some patients to sinus diseases by causing obstruction that can lead to inflammatory disease. A Haller (Infraorbital) cell is such an anomaly that can narrow the ostiomeatal

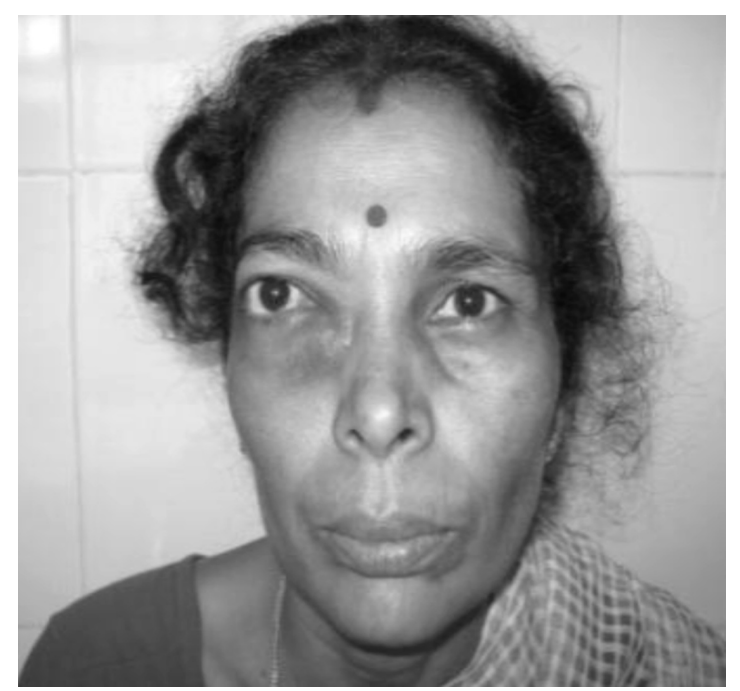

Figure 1. Patient with right-sided proptosis and local skin inflammation. Photo printed in full with permission. 


\section{CASE REPORTS}
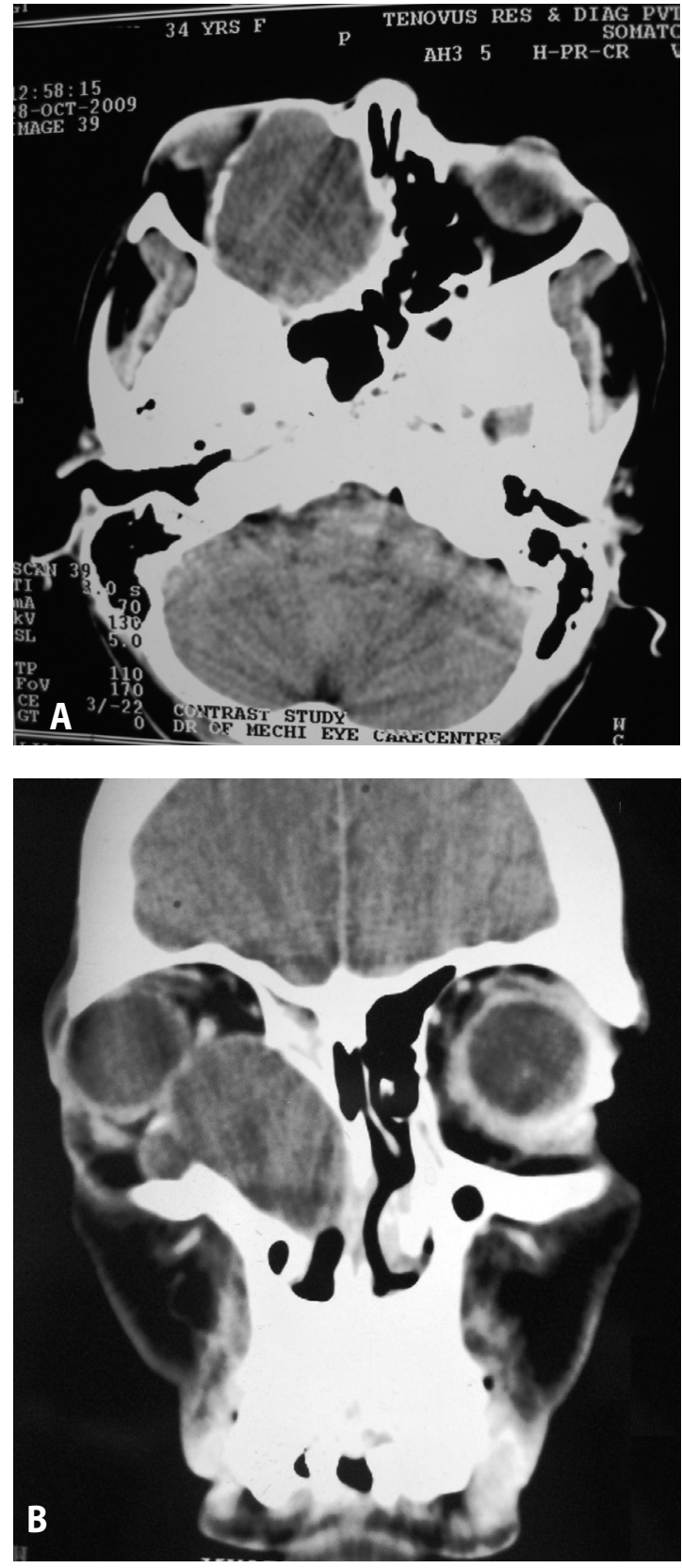

Figure 2 A \& B. Axial and Coronal computed tomography images showing right Haller cell encroaching into the orbit (causing proptosis), maxillary antrum and nasal fossa.

complex if large. ${ }^{4}$ As migrated anterior ethmoidal air cells that pneumatize the roof of the maxillary sinus or floor of the orbit, they are also termed 'orbitoethmoidal' or 'maxilloethmoidal' cells. Easily seen on coronal computerized tomography (CT) of the sinuses, ${ }^{5}$ they have been described as well-defined, round, oval or teardrop-shaped, unilocular or multilocular radiolucencies with smooth borders that may or may not appear corticated, located medial to the infraorbital foramen. ${ }^{6}$



Figure 3. Intraoperative photograph showing tip of the cannula in the Haller cell

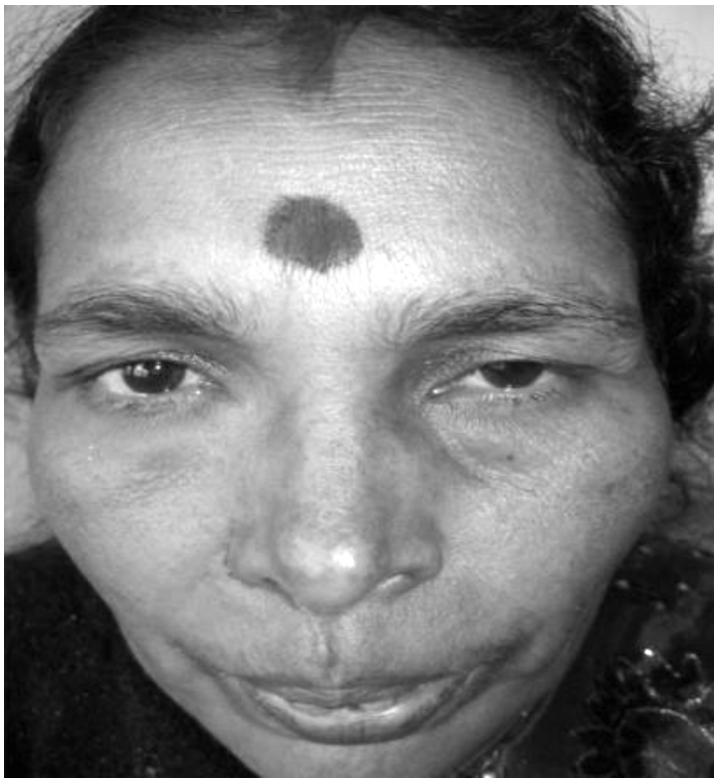

Figure 4. Post-operative appearance of the patient. Photo printed in full with permission.

A Haller cell can be solitary or multiple and can be classified as small, medium or large. ${ }^{7}$ Asymptomatic in a majority of patients, ${ }^{1}$ Haller cells may present with various symptoms. Progressive frontal headache was one of the presenting complaints of our patient. In a study by Hammad et al. sinus CT revealed Haller cell in 5 (18.75\%) of 40 patients with rhinogenic headache. ${ }^{8}$ Sinusitis can result from infundibular obstruction with or without another anatomical variation such as concha bullosa. 


\section{CASE REPORTS}

In the absence of frank sinusitis, blockage of the sinus drainage pathway may result in sinus malventilation, vacuum headache and pressure headache. Headache was mostly located at frontal area (64\%) followed by face and periorbital area (36\% each). ${ }^{8}$

Our case also presented with sinusitis and proptosis. Haller cell may cause recurrent or chronic sinusitis and persistent sinugenic headache without significant findings on physical examination including nasal endoscopy and the presence of a large ethmoidal cell on coronal CT in a patient with corresponding symptoms deserves consideration as the potential cause of the symptoms. ${ }^{9}$ Orbital involvement from Haller cell is very rare and infrequently reported in the literature. Sebrechts et al. reported three cases of unilateral orbital edema resulting from inflammation of ipsilateral Haller cell. ${ }^{10}$ We believe proptosis resulting from a large Haller cell as we found in our case has not been reported in the English literature.

The management of pathologic Haller's cell is usually approached endoscopically through the middle meatus using a microdebrider to remove the uncinate process including its inferior attachment. ${ }^{11}$ The cell is visualized and carefully uncapped with a curved microdebrider blade and then its inferior and medial portions are carefully removed. The procedure widens the infundibulum and the outflow tract of the maxillary sinus. The superior portion of the Haller's cell is not dissected so that integrity of the orbital floor is not disturbed. ${ }^{11}$ A previous study reported that overall improvement in headache intensity after endoscopic surgical intervention was statistically significant $(P=0.003) .{ }^{8}$ In our case as the swelling presented more subcutaneously just below the medial canthus than in the nasal cavity, we opted for lateral rhinotomy approach. This avoided difficulty in finding the antrum due to its distortion from a large cell situated above as well as inadvertent orbital entry. This approach also provided quick exposure to the operative area. However, this approach may be feasible only for Haller cells large enough to cause cosmetic deformity of overlying nasal skin. Further experience may be necessary to prove its effectiveness and formulate indications for its use.

\footnotetext{
ACKNOWLEDGEMENT

The authors would like to thank the Principal, Gauhati Medical College and Hospital for allowing us to conduct the work.

REFERENCES

1. Stallman JS, Lobo JN, Som PM. The incidence of concha bullosa and its relationship to nasal septal deviation and paranasal sinus disease. AJNR Am J Neuroradiol. 2004 Oct; 25(9):1613 1618.

2. Stackpole SA, Edelstein DR. Anatomic relevance of Haller cells in sinusitis. Am J Rhinol. 1997 May-Jun; 11(3):219-223.

3. Ahmad M, Khurana N, Jaberi J, Sampair C, Kuba RK. Prevalence of infraorbital ethmoid (Haller's) cell on panoramic radiographs. The Saudi Dental Journal. 2006 May; 101(5):658-661.

4. Stammberger H, Hawke M. Endoscopic and Radiologic Diagnosis. In: Essentials of Endoscopic Sinus Surgery. St. Louis, Missouri: Mosby;1993.p.92.

5. Yanagisawa E, Citardi MJ. Endoscopic view of the infraorbital ethmoid cell (Haller cell). Ear Nose Throat J. 1996 Jul; 75(7):406-407.

6. Raina A, Guledged MV, Patil K. Infraorbital ethmoid (Haller's) cells: a panoramic radiographic study. Dentomaxillofac Radiol. 2012 May; 41(4):305-308.

7. Balasubramanian T. Infected Haller cell. Radiology image of the issue. Otolaryngology Journal online. 2012 Jul; 2(1). [cited 2015 Mar 9]. Available from: http://works.bepress.com/drtbalu/48

8. Hammad MS, Gomaa MA. Role of anatomical nasal abnormalities in rhinogenic headache. Egypt J Ear, Nose, Throat Allied Sci. 2012 Mar; 13(1):31-35.

9. Wanamaker HH. Role of Haller's cell in headache and sinus disease: a case report. Otolaryngol Head Neck Surg.1996 Feb; 114(2):324-327.

10. Sebrechts H, Vlaminck S, Casselman J. Orbital edema resulting from Haller's cell pathology: 3 case reports and review of literature. Acta Otorhinolaryngol Belg. 2000; 54(1):39-43.

11. Christmas DA, Mirante JP, Yanagisawa E. Endoscopic view of the removal of an obstructing Haller's cell. Ear Nose Throat J. 2006 Jun; 85(6): 360-1.
} 